\title{
A Novel Karyotype in a South Indian Tettigonid. (Subfam: Listroscelinae-Orthoptera)
}

\author{
N. V. Aswathanarayana* \\ Department of Zoology (Rtd.), University of Mysore, Mysore 570 006, India \\ Accepted March 16, 1998
}

\begin{abstract}
Summary 1) During a chromosomal survey of the tettigonids an unusual specimen No. 207 (in our list of specimens) was discovered which is tentatively placed under the genus Euhexacentrus of the subfam: Listroscelinae. 2) Euhexacentrus sp. (specimen No. 207) is unusual among the tettigonids as its karyotype has the lowest chromosome number of $2 n=9(8 A+X)$ with 4 pairs of metacentric autosomes and a smaller acrocentric $X$ chromosome. 3) This karyotype is compared with the karyotype of E. annulicornis, whose chromosome number is $12(10 \mathrm{~A}+\mathrm{XY})$ and are all metacentric. 4) The karyotype details of all the known species of the subfam: Listroscelinae are presented for comparison along with the present Euhexacentrus sp. 5) The probable evolution of the present karyotype is discussed.
\end{abstract}

Karyotype dynamism is of paramount importance in evolution which may involve one or more structural mechanisms in the chromosomes. The chromosome study in the tettigonid group is very much less when compared with the short horned grasshoppers (Acridids). Asana et al. stated as early as 1938 that "Our knowledge of the tettigonid chromosomes is yet too scanty" which holds good even today though reports and descriptions of chromosomes of some species are added periodically.

Comparatively chromosome studies are most extensive in the subfamily Phaneropterinae in the tettigonid group, which exhibits a wide range of chromosome number from 16-39 (Ferreira 1977). But with the description of the lowest chromosome number of $2 n=12$ in Euhexacentrus annulicornis (Subfam. Listroscelinae, Aswathanarayana and Ashwath 1985) the diploid number varies from 12-39. The present study deals with the chromosomes of a long horned grasshopper specimen No. 207 which has a further lower number not so far encountered and discusses its possible cytological links within this group.

\section{Material and methods}

Two young individuals, one male and another female specimen Nos. 207 and 208 were collected in the University campus, Manasa Gangotri, Mysore, South India. The chromosome preparation was made by Air-dry-Giemsa method using hepatic caecae. Only male specimen No. 207 yielded some good metaphases. Since, the present specimen had the lowest chromosome number, a thorough search of the entire area was made to collect such individuals for more than two and half years. But the attempts proved a futile exercise which means such individuals are rare. However, referring to the vast literature on the subject it was found that the specimen No. 207 had all the characteristics described by Hobard (1922) and Burman (1995). Thus the specimen is tentatively placed under the genus Euhexacentrus of the subfam. Listroscelinae.

\footnotetext{
* Correspondence address: No. 290/3, 34th 'A' Cross, 9th Main Road, 4th Block, Jayanagar, Bangalore-560 011, India.
} 


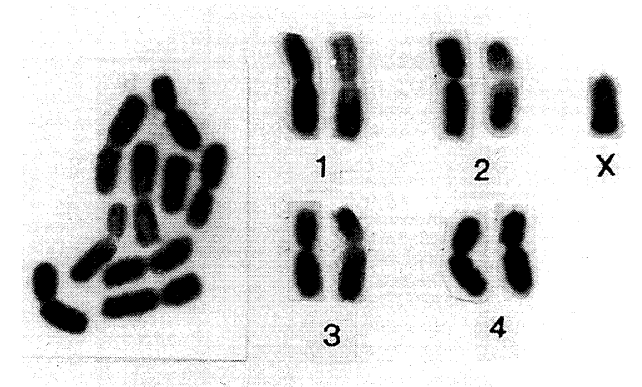

Fig. 1. Male metaphase and karyotype of Euhexacentrus sp. (specimen No. 207).

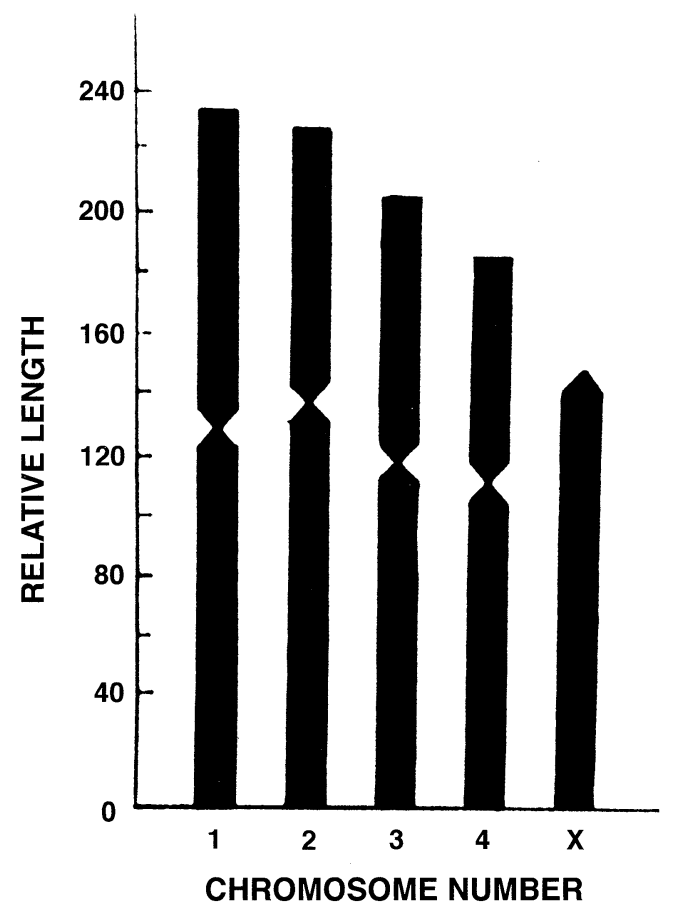

Fig. 2. Idiogram of Euhexacentres sp.

\section{Results and discussion}

Specimen No. 207 (Euhexacentrus sp.) is a beautiful and interesting grasshopper. Its karyotype is unusual and novel among tettigonids with the outstanding features of the lowest chromosome number of $2 n=9(8 \mathrm{~A}+\mathrm{X})$ with 4 pairs of metacentric autosomes and a smaller acrocentric $\mathrm{X}$ chromosome not encountered so far. So it assumes much importance in the karyotype history of tettigonids (Figs. 1, 2).

Now that the specimen No. 207 is tentatively identified as Euhexacentrus sp. belonging to subfam. Listroscelinae, a brief account of the chromosomes of this subgroup is presented (Table 1). The first report of the chromosomes of this family is of Hareyama (1937) who reported the male diploid number of $33(32 \mathrm{~A}+\mathrm{X})$ in Hexacentrus japonicus. Though the details of the chromosomes are not clear, it appears that the autosomes are all acrocentric with a sub-metacentric/metacentric $\mathrm{X}$ chromosome. Later Asana et al. (1938) described in H. mundus and H. annulicornis a chromosome complement of $31(30 \mathrm{~A}+\mathrm{X})$ in both the species with all acrocentric autosomes and an $\mathrm{X}$ chromosome with a sub-median constriction. In Yorikella picta, White et al. (1967) reported a diploid number of $20(18 \mathrm{~A}+\mathrm{XY})$ consisting of 10 metacentrics and 8 acrocentric with a neo-XY sex mechanism. But Yorkiella sp. 1 (White et al. 1967) and Yorkiella sp. 2 (Ferreira 1969) showed 31 $(30 \mathrm{~A}+\mathrm{X})$ chromosomes with all acrocentric autosomes and a metacentric X. In 1978, Kacker and Singh presented the female karyotype of Xiphidiopsis straminula containing 34 chromosomes $(32 \mathrm{~A}+\mathrm{XX})$ having a pair of sub-metacentric, 15 pairs of acrocentric autosomes and a fairly large metacentric X chromosomes. In Xiphidiopsis sp. Aswathanarayana and Uma (1992) have also described in the male $2 n=33(32 \mathrm{~A}+\mathrm{X})$ but with a difference. It had one pair of metacentric, 2 pairs of sub-metacentric (one large and one small), 3 pairs of sub-acrocentric and 10 pairs of acrocentric chromosomes. A lower number of $12(10 \mathrm{~A}+\mathrm{XY})$ was reported in Euhexacentrus annulicornis by Aswathanarayana and Ashwath (1985) with 5 pairs of metacentric (4 large and one very small) and 


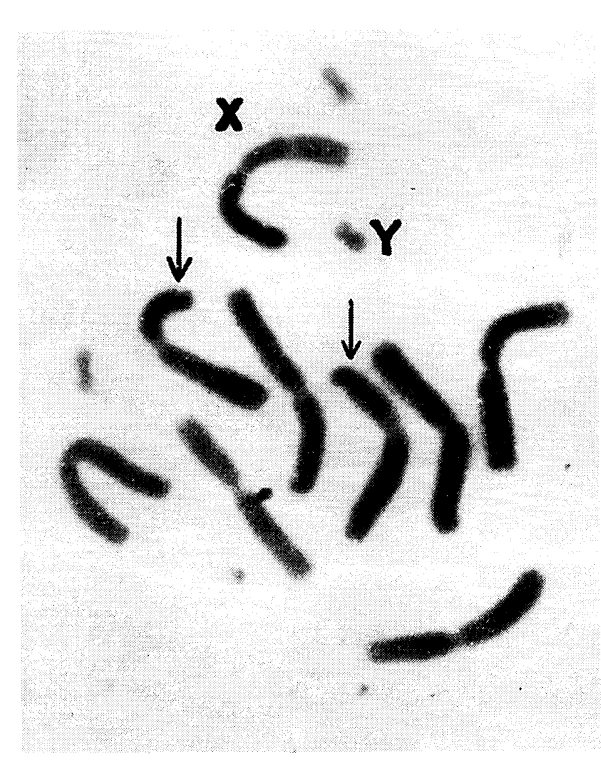

Fig. 3. Male metaphase of Euhexacentrus annulicornis. Arrow indicates the secondary constriction.

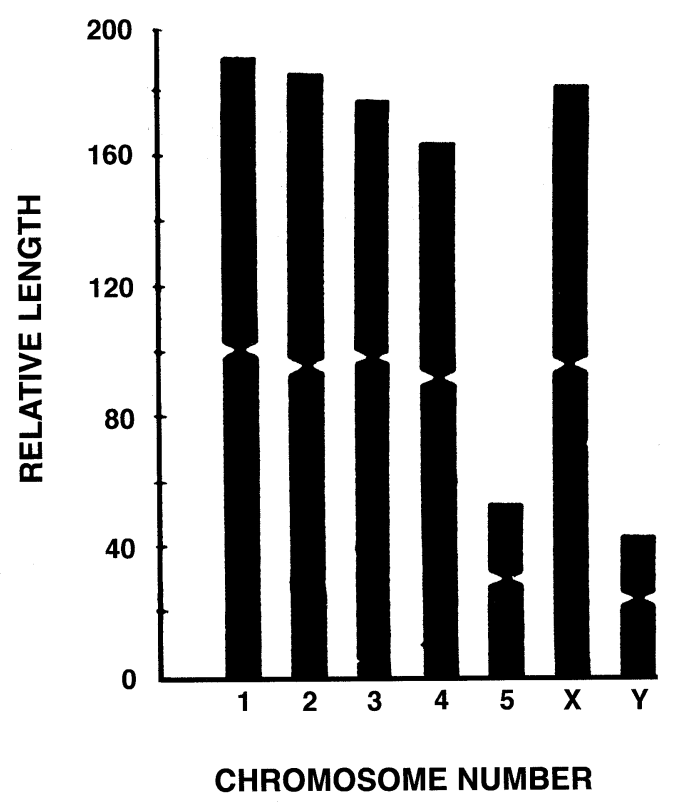

Fig. 4. Idiogram of E. annulicornis.

an XY sex mechanism (Figs. 3, 4). The neo-XY mechanism could not be confirmed as the necessary meiotic stages were not available. The $\mathrm{X}$ chromosome was a little smaller than the largest autosomal pair as identified by C-banding. The smaller $\mathrm{Y}$ was completely heterochromatic.

The general karyotypes of Hexacentrus and Xiphidiopsis are established to be $2 \mathrm{n}=33$. But Yorkiella has $2 \mathrm{n}=31$. The autosomes of Xiphidiopsis species have undergone modification by possessing biarmed chromosomes due to pericentric inversions. Both $H$. mundus and $H$. annulicornis which have $2 n=31$ are considered to be a step more advanced by tandem fusion of $H$. japonicus karyotype $(2 n=32 A+X)$. With the above details, the general karyotype of subfam. Listroscelinae is considered to be $2 \mathrm{n}=33$.

It is possible that Hexacentrus species with $2 n=33$ might have given rise to E. annulicornis $(2 \mathrm{n}=12 \rightarrow 10 \mathrm{~A}+\mathrm{XY})$ having all metacentrics by the mechanism of centric fusion, tandem fusion and pericentric inversion. Since, many structural changes are involved in the process, the differentiation must have taken considerable time.

As the karyotype of specimen No. 207 (Euhexacentrus sp.) is so different from the karyotypes of other Listroscelinae having the lowest chromosome number with large metacentric autosomes and a smaller acrocentric X chromosome, only the autosomes can be derived from Hexacentrus species by centric fusion, tandem fusion and pericentric inversion or from E. annulicornis by centric fission, pericentric inversion and tandem fusion. The $\mathrm{X}$ chromosome of the present case can not fit into the pattern of the other species of the subfamily. So it is not possible to say whether deletion is responsible for shortness. For the comparison of the karyotype morphometric data and C-banding are imperative which are not available except for E. annulicornis. However, the idiograms of the present case (Euhexacentrus sp., Fig. 2) and that of E. annulicornis (Fig. 4) presented here gives the imperssion that they are related in one feature or the other.

When $2 \mathrm{n}=12(10 \mathrm{~A}+\mathrm{XY})$ karyotype was discovered in E. annulicornis we thought further reduction in chromosome number was remote as all the chromosomes were metacentrics. But with the discovery of $2 \mathrm{n}=9(8 \mathrm{~A}+\mathrm{X})$ in the specimen No. 207 (Euhexacentrus sp.) one can predict the occurrence of still lower chromosome numbers by repeated random sampling.

Though the extent of variation in the chromosome number in the subfam. Listroscelinae 
Table 1. Showing the karyotype details of the species of subfam: Listroscelinae

\begin{tabular}{|c|c|c|c|c|c|}
\hline & Species & $2 n$ & Autosomes & Sex chromosomes & Authors \\
\hline \multicolumn{6}{|c|}{ I Hexacentrus } \\
\hline & 1 H. japonicus & 33 & 32 acro & $\mathrm{X}$ large V shaped & Hareyama (1937) \\
\hline & 2 H. mundus & 31 & 30 acro & $\mathrm{X}$ large $\mathrm{Sm}$ & Asana et al. (1938) \\
\hline & 3 H. annulicornis & 31 & 30 acro & $\mathrm{X}$ large Sm & Asana et al. (1938) \\
\hline \multicolumn{6}{|c|}{ II Xiphidiopsis } \\
\hline & 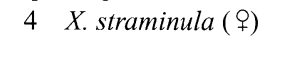 & 34 & $\begin{array}{l}2 \mathrm{Sm} \\
30 \text { acro }\end{array}$ & $\mathrm{X}$ large meta & Kacker and Singh (1978) \\
\hline & 5 Xiphiopsis sp. & 33 & $\begin{array}{l}2 \text { med. meta } \\
4 \mathrm{Sm} \\
6 \text { sub acro } \\
20 \text { acro }\end{array}$ & $\mathrm{X}$-large meta & $\begin{array}{l}\text { Aswathanarayana } \\
\text { and Uma (1992) }\end{array}$ \\
\hline \multirow[t]{4}{*}{ III } & Yorkiella & & & & \\
\hline & $6 \quad$ Yorkiella sp. 1 & 31 & 30 acro & $\mathrm{X}$ large meta & White et al. (1967) \\
\hline & $7 \quad$ Yorkiella sp. 2 & 31 & 30 acro & $\mathrm{X}$ large meta & Ferreira (1969) \\
\hline & $8 \quad$ Y. picta & 20 & $\begin{array}{l}10 \text { meta } \\
8 \text { acro }\end{array}$ & $\begin{array}{l}\text { Large X meta } \\
\text { Y acro } \\
\text { Neo XY }\end{array}$ & White et al. (1967) \\
\hline \multirow[t]{3}{*}{ IV } & Euhexacentrus & & & & \\
\hline & 9 E. annulicornis & 12 & $\begin{array}{l}8 \text { large meta } \\
2 \text { meta minute }\end{array}$ & $\begin{array}{l}\mathrm{X} \text { large meta } \\
\text { Y meta minute }\end{array}$ & $\begin{array}{l}\text { Aswathanarayana } \\
\text { and Ashwath (1985) }\end{array}$ \\
\hline & $\begin{array}{l}10 \text { Specimen No. } 207 \\
\text { Euhexacentrus sp. }\end{array}$ & 9 & 8 large meta & $\mathrm{X}$ med. acro & Present study \\
\hline
\end{tabular}

ranges between 9 and 33 including the present case (Euhexacentrus sp.), extensive studies in a large number of species are necessary to establish accurately the karyotype evolution.

The karyotype details of the species of subfam. Listroscelinae are presented for comparison (Table 1).

\section{Acknowledgements}

Grateful thanks are due to the University Grants Commission, New Delhi for the award of the project and to the University of Mysore (India) for the facilities. I profusely thank Dr. A. K. Singh, Zoological survey of India, Calcutta for making available the literature on tettigonids and to Dr. N. A. Manjunath, Department of Microbiology and Cell Biology, Indian Institute of Science, Bangalore-12 (India) for the technical help. Thanks are also due to Sri. R. B. Ravi Varma for neat typing of the manuscript.

\section{References}

Asana, J. J., Makino, S. and Niiyama, H. 1938. A Chromosomal survey of Indian insects, I Morphology of the Chromosomes in eight species of the Locustidae. J. Fac. Sci., Hokkaido Univ. Ser. 6: 211-234.

Aswathanarayana, N. V. and Ashwath, S. K. 1985. Karyology of Tettigonids (Class: Insecta). Chromosomes and constitutive heterochromatin in Euhexacentrus annulicornis. Stol. Subfam: Listroscellinae. Entomon. 10: 97-101.

- and Uma, K. 1992. A new Karyotype in the genus Xiphidiopsis (Fam: Tettigoniidae, subfam: Listroscelinae, Class: Insecta). J. Mys. Univ. Sect B 32: 289-291.

Burman, R. S. 1955. Tettigoniidae-Orthoptera, Zool. Surv. India, State Fauna Series. Fauna of Meghalaya part 3: $279-290$.

Ferreira, A. 1969. Chromosome survey of some Australian Tettigoniids (Orthoptera-Tettigoniodea). Two species with neoXY sex-determining mechanism. Cytologia 34: 511-522.

-1977. Cytology of Neotropical Phaneropteridae (Orthoptera-Tettigoniodae). Genetica 47: 81-86.

Hareyama, S. 1937. On the chromosomes in Spermatogenesis in some insects of Locustidae. Zool. Mag. (Tokyo) 49: 122.

Hebard, M. 1922. Studies in Malayan, Melanesian and Australian Tettigoniidae (Orthopetra). Proc. Acad. Nat. Sci. Philad. 
74: $121-299$.

Kacker, R. K. and Singh, A. K. 1978. Chromosomes of Xiphidiopsis straminula (Walker) (Orthoptera, Tettigoniidae, Meconematinae). Bull. Zool. Surv. India 1: 57-59.

White, M. J. D., Mesa, A. and Mesa, R. 1967. Neo-XY sex chromosome mechanisms in two species of Tettigoniodea (Orthoptera). Cytologia 32: 190-199. 